\title{
Herencia Afrodescendiente en el caserío Valle del Lili
}

$\square$ AFRO-DESCENDANT HERITAGE IN THE HERMIT OF VALLE DE LILI

HERANÇA AFRODESCENDENTE NO CASARIO DE VALLE DEL LILI

\author{
Alejandro Astorquiza1 / alejoastor@yahoo.com
}

\section{Resumen}

El proyecto de investigación pedagógica "Herencia Afrodescendiente en el caserío Valle del Lili”, fue realizado por estudiantes del grado 5 de educación básica primaria, de la Institución Educativa INCOLBALLET de Cali.

Para dar inicio al proyecto, el grupo "Investigadores del Patrimonio del Valle del Lili” planteó varias preguntas y la que más se acercó a sus intereses fue: ¿Qué aprendizajes nos heredaron los afrodescendientes esclavos y libertos de la Hacienda Cañasgordas a los habitantes del Caserío Valle del Lili?

Para resolver la pregunta acudimos a las abuelas del caserío y a fuentes escritas, de donde obtuvimos información relacionada con la historia de la Hacienda Cañasgordas.

\section{Palabras clave:}

Hacienda, cañasgordas, valle del Lili, caserío, esclavitud, afrodescendencia

\section{Abstract}

The educational research project "Afro-descendant heritage in the hermit of Valle del Lili" was conducted by fifth grade students of the Educational Institution INCOLBALLET in Cali.

To begin the project, the group of "Researchers of the Heritage of Valle del Lili" posed several questions and the one closest to their interest was: What lessons were inherited to the inhabitants of the hermit of Valle del Lili by afro-descendant slaves and freedmen at the Cañasgordas Ranch?

To answer the question, we turned to the grandmothers who lived in the hermit and to written sources, from where we were able to collect information related to the history of the Cañasgordas Ranch.

\section{Keywords:}

Ranch, Cañasgordas, Valle del Lili, small village, slavery, afro-descendant.

\section{Resumo}

O projeto de pesquisa pedagógica "Herança Afrodescendente no casario Valle de Lili", foi realizado por estudantes de quinto ano de educação básica primaria, da Instituição Educativa INCOLBALLET de Cali.

Para iniciar o projeto, o grupo "Investigadores do Patrimônio de Valle del Lili” fez várias perguntas das quais a mais adequada segundo seus interesses foi: Que aprendizagens são herança dos afrodescendentes escravos e livres da Fazenda Cañasgordas para os habitantes do casario de Valle del Lili?

Para resolver essa questão, falamos com as avós do casario e consultamos em fontes escritas, onde obtivemos informação relacionada com a história da Fazenda Cañasgordas.

\section{Palavras chave:}

Fazenda, Cañasgordas, Valle del Lili, aldeia, escravidão, afrodescendência.

1 Maestro Oficial, Institución Educativa Incolballet sede Cañasgordas Cali, Valle del Cauca 
El presente proyecto de investigación pedagógica, titulado "Herencia Afrodescendiente en el caserío Valle del Lili", de la Institución Educativa Técnica de Ballet Clásico INCOLBALLET sede Cañasgordas, de la ciudad de Cali, en el Valle del Cauca, Colombia, se inscribe en el marco del megaproyecto Construcción de una cultura ciudadana de ciencia, tecnología e innovación en niños, jóvenes, maestros y comunidad de todo el departamento del Valle, Occidente, a través de la Convocatoria 2015 del Programa Ondas ColcienciasConvenio Universidad del Valle y el Instituto de Educación y Pedagogía.

El Primer momento en el proceso de la implementación del proyecto de investigación consistió en seleccionar entre los estudiantes del grado quinto de educación básica primaria a los más interesados en vincularse al grupo de investigación; luego generamos la motivación para darle un nombre al grupo y, así mismo, crear un logo y su respectivo eslogan, buscando propiciar sentido de pertenencia al grupo. De esta manera, surgió de las propuestas de nuestros estudiantes el nombre Investigadores del Patrimonio del Valle del Lili, con el eslogan "Liberar el arte y el conocimiento", tomando en cuenta que somos una institución de formación artística.

Una vez definimos nuestra visión, y a través de la dinámica de la lluvia de ideas, surgieron preguntas espontáneas; después planteamos la definición de un tema en común que todos quisieran investigar (historia del caserío, la hacienda Cañasgordas, esclavitud, afrodescendencia, patrimonio, río, Valle del Lili). Luego realizamos una construcción colectiva de las preguntas con diálogo entre los todos los participantes; fuimos seleccionando las mejores preguntas y, posteriormente, volvimos a hacer el proceso de reflexión. Los estudiantes escogieron y reelaboraron la pregunta final, y así quedó propuesta:

¿Qué aprendizajes nos heredaron los afrodescendientes esclavos y libertos de la hacienda Cañasgordas a los habitantes del Caserío Valle del Lili?

Un alto porcentaje de los estudiantes del grado quinto de educación básica primaria de Incolballet sede Cañasgordas desconocían el contexto histórico y ancestral de su propio origen como descendientes de esclavizados negros de la hacienda Cañasgordas. Según el libro El alférez real, de Eustaquio Palacios, "Cañasgordas era la hacienda más grande, más rica y más productiva de todas cuantas había en el Valle" (p. 26). En Cali, para 1789 , según el riguroso empadronamiento hecho en 1793, el recinto de la ciudad solo tenía 6548 habitantes; de éstos, 1106 eran esclavos (Palacios Eustaquio, p. 53-2000). En la misma obra, relata José Eustaquio Palacios.: "De estos más de 200, todos negros, de uno y otro sexo y de toda edad; estaban divididos por familias y cada familia tenía su casa por separado, pertenecían a la hacienda Cañasgordas" (p. 28).

Por tal motivo, y teniendo en cuenta la aún viva tradición oral de descendientes directos de estos primeros moradores afrodescendientes libertos de la hacienda, vimos la oportunidad de iniciar ese contacto pedagógico con los niños y la historia de su entorno. Esta dinámica inicial se transformaría luego, a raíz del interés y de las preguntas de los estudiantes, en la temática final de este proyecto.

A continuación, transcribimos las respuestas dadas por varios miembros del grupo a la pregunta de investigación.

"Es bueno hacer esta investigación porque uno aprende más de la historia del Valle del Lili." (María Victoria Duarte)

"Porque es importante conocer la historia de nuestra escuela, dónde está situada y la comunidad también la deben (sic) saber porque viven aquí." (Zharick Dayana Prado)

"Porque es importante que la comunidad sepa sobre la historia, sobre los antepasados." (Valeria Carvajal)

"Es importante conocer nuestra historia porque tenemos conocimientos nuevos sobre la historia del Valle del Lili y de la hacienda Cañasgordas y también cómo se formó la vivienda..." (Paola Diossa)

"También es bueno conocer cómo fue la esclavitud y cómo trajeron los afros a nuestro país y especialmente a Cañasgordas y al Valle del Lili." (Paola Diossa)

"Es importante que todas las personas sepan la historia de la comunidad y sobre la hacienda 
Cañasgordas para que puedan informarse sobre qué pasó y se puedan preguntar sobre la comunidad y hay muchas preguntas, muchas ideas $y$ respuestas buenas." (Angelly González).

"Es importante para que las personas sepan la historia del Valle del Lili y para que vengan al caserío. Es importante para saber y conocer la historia del Valle del Lili y para que se pase de generación en generación." (Gabriela Ipia)

En este proceso de investigación surgieron las propuestas de divulgación, que consistieron en dar a conocer y difundir los aprendizajes heredados por los habitantes afrodescendientes de los esclavos y los libertos de la hacienda Cañasgordas, a través de un folleto impreso. También, rescatar el patrimonio histórico y cultural del caserío Valle del Lili mediante el diálogo de saberes y la historia oral, para fortalecer la identidad de los estudiantes y la comunidad del caserío Valle del Lili, y, así mismo, para reflexionar con la comunidad e incrementar el nivel de conocimiento de los estudiantes sobre la historia de los antiguos esclavos y los primeros libertos de la antigua hacienda Cañasgordas.

La ruta de investigación se planteó teniendo en cuenta las siguientes estrategias:

- Identificación de personas que han vivido la experiencia

- Salida de campo

- Entrevistas

- Diseños de actividades y materiales

En el proceso de investigación, desarrollamos el plan de actividades con las personas que han vivido las experiencias: los habitantes del caserío Valle del Lili, quienes son descendientes directos de los primeros pobladores.

Una de las más reconocidas abuelas del caserío, y quien nos aportó información oportuna, fue la abuela de Mateo, doña Stella Barona. Ella fue la protagonista en nuestro proceso de investigación; realizamos el intercambio con la abuela a través de cuatro talleres de gastronomía típica y de charlas documentadas con los estudiantes, durante las cuales escuchamos el tema por tratar, e hicimos preguntas y las registramos en el diario de campo. Los talleres de cocina tradicional fueron agradables conversatorios en la casa de la abuela, mientras preparábamos el "dulce de papaya verde o cabellos de ángel". Con posterioridad a los talleres, tuvimos el segundo encuentro con la abuela Stella, en el aula de clase, mientras preparábamos el arroz con leche; además, le hicimos una corta entrevista, registrada en video. El tercer encuentro fue, nuevamente, en "la casa paterna", mientras preparábamos el champús tradicional caleño, conocido como "el champús de Lola". Realizamos el cuarto taller, finalmente, durante una parada en el trayecto de la salida de campo, mientras preparábamos la "mazamorra de maíz pilao"; pudimos contrastar estas recetas en el libro Fogón de negros, de German Patiño-2010.

Planteamos la salida de campo por el caserío, por el área geográfica del caserío Valle del Lili, diseñada con los estudiantes del grupo de investigación, con sentido de investigación etnográfica, buscando con los niños resignificar los espacios más importantes del lugar, la historia del Valle del Lili y los personajes del caserío; para ello, nos dividimos en tres equipos de trabajo: El equipo 1 se encargó del registro fotográfico y de video. El equipo 2, integrado por los niños y niñas que viven en el caserío, fue el guía. El equipo 3 fue conformado por los dibujantes de los trazados del recorrido, los planos y los senderos del caserío.

\section{El Co-relato}

Para dar inicio a esta fase, tuvimos en cuenta hacer los contactos previos con las personas de la comunidad, con el fin de que nos permitieran hacer el recorrido y estuvieran preparados para recibirnos; fueron ellos nuestros anfitriones. Iniciamos el recorrido, según el plano diseñado por los dibujantes, por la cabecera del río Lili, en el lugar denominado por los habitantes como "el hueco". Allí, según la información de los pobladores, aprendimos que el río cruza todo el Valle del Lili, hasta desembocar en el río Cauca, y se llama así porque antiguamente este territorio era habitado por los indígenas de la tribu de los lilies.

A mitad del recorrido y sobre el margen izquierdo del río, pudimos ver, en unas fotografías antiguas que nos mostró 
otra abuela, que cuando el río Lili se crecía, inundaba todo el sector. También pudimos apreciar los vestigios de un puente de cemento que comunicaba al caserío con la hacienda Cañasgordas; este, según nuestros informantes, fue demolido sin permiso de la comunidad.

Un poco más abajo y sobre el mismo margen del río Lili, otra anfitriona, doña Elena, nos mostró un álbum que contenía registros fotográficos de la biodiversidad del sector; en él pudimos reconocer las nutrias del río, guatines y una variedad de aves de río. La abuela Stella, quien nos acompañó en gran parte del recorrido, aprovechó para narrarnos historias sobre los esclavos y los libertos de la hacienda Cañasgordas y sobre el origen del caserío.

Una vez terminamos el recorrido, nos dedicamos a hacer los mapas parlantes del barrio. Posteriormente, en clase, contrastamos estos mapas con otros mapas técnicos del caserío, existentes en la institución.

Con los estudiantes del grupo Investigadores del Patrimonio del Valle del Lili, diseñamos actividades y materiales durante todo el recorrido de la investigación, preparamos dibujos, carteleras, presentaciones musicales, exposiciones y mapas de la salida de campo por el caserío. Utilizamos la mayor parte de estas actividades y materiales como estrategia de divulgación.

Consideramos muy importante haber tenido la oportunidad de dialogar con descendientes de esclavos y de libertos de la hacienda Cañasgordas para conocer los estilos de vida, el vestuario de la época, la alimentación, las ceremonias, las formas de castigo, la mitología y las actividades socioeconómicas realizadas por los esclavos en la hacienda. Estos aprendizajes fueron transmitidos a los estudiantes gracias a un proceso de narración oral que los familiares de los primeros pobladores del caserío, esclavos libertos de la hacienda Cañasgordas, han ido transmitiendo espontáneamente de generación en generación a sus hijos, sus nietos y sus bisnietos; muchos de ellos asisten a nuestra institución.

Además de lo anterior, los integrantes del grupo de investigación apropiaron la información, porque fue obtenida de manera muy pedagógica, afectiva y social, gracias a la forma como las abuelas del caserío transmitieron sus conocimientos y sus experiencias. De esta forma, logramos sustentar la experiencia en varios escenarios pedagógicos y los estudiantes hablan con espontaneidad sobre lo que aprendieron y sobre lo que más les impactó en el proceso de investigación.

Con esta investigación logramos documentar una parte de la historia oral del caserío, la cual tuvo referentes conceptuales de la tesis de grado del coordinador de la sede, señor Jorge Humberto Victoria Zuluaga; así mismo, logramos seleccionar una serie de fotografías en el archivo fotográfico de diferentes épocas del caserío, y las cuales clasificamos en: población, viviendas, contexto geográfico, proceso, vestigios de las primeras viviendas, puentes, vía férrea, linderos y antigua carretera Cali-Popayán.

En este proceso de rescate del patrimonio histórico y cultural del caserío, aprendimos a dialogar con las personas del caserío. También compartimos los hallazgos con los estudiantes de la sede, con los maestros y con los directivos de Incolballet; así mismo, logramos fortalecer la identidad de los estudiantes, de la comunidad educativa y de la comunidad del caserío Valle del Lili.

Por otra parte, logramos identificar El alférez real (publicado en 1886) como un referente de comparación con las fuentes primarias obtenidas o narradas por las abuelas del caserío, y así encontramos valiosas coincidencias de nombres de personajes de la obra con nombres propios de los afrodescendientes del caserío. Algunas costumbres perviven en las pocas familias que quedan; por tal motivo, podemos decir que las historias contadas por las abuelas nos sirvieron para incrementar el nivel de conocimientos sobre la historia de los antiguos esclavos y los primeros libertos de la hacienda Cañasgordas de Cali, y dejamos, como un insumo para promover ante la Academia de Historia de Cali, declarar el caserío Valle del Lili como patrimonio histórico, y, así mismo, declarar los conocimientos a través de la oralidad de las abuelas del caserío como un patrimonio inmaterial y cultural de Cali.

Entre otros hallazgos logrados por el grupo de investigación, podemos destacar: 
- Recetas de cocina tradicional de los afrodescendientes de la hacienda Cañasgordas.

- Conocimientos propios sobre gastronomía, cultura y tradición, recibidos por los descendientes directos de los primeros pobladores del caserío con historia oral viva de las experiencias y las vivencias de los antiguos esclavos y los libertos de la hacienda.

- Un valioso archivo fotográfico, ubicado en la sede Cañasgordas, de distintos momentos del caserío Valle del Lili, que ampliaron el conocimiento de su proceso de transformación y de organización comunitaria.

- Vestigios de la antigua "vía férrea" en el trayecto Cali-Popayán (rieles y mural alegórico) y de las primeras viviendas del caserío con algunas modificaciones, como la denominada "Casa Paterna".

- Conocimiento sobre formas de vestir, cortejos, castigos y creencias de los esclavos en la antigua hacienda.

- Conocimientos sobre la historia de poblamiento del caserío Valle del Lili, a través de la investigación y de su caracterización del caserío.

- Relato oral que da testimonio sobre el territorio del caserío, el cual no fue una invasión, sino que, en su momento (1852 aproximadamente), fue una donación de 90 plazas a los esclavos libertos, por parte del alférez real, don Manuel de Caicedo y Tenorio, coronel de milicias disciplinadas, alférez real, regidor perpetuo de la muy noble y leal ciudad de Cali.

- Fotografías de los vestigios de los puentes de cemento y madera, de los rieles y del puente y de la estación férrea que comunicaba la hacienda y el caserío. Estos puentes, según las abuelas, hace varias décadas fueron demolidos sin el consentimiento de la comunidad.

- Un verdadero interés, demostrado por los estudiantes, en conocer la historia del caserío; espe- cialmente, sobre la esclavitud y la vida en la antigua hacienda Cañasgordas de la ciudad de Cali, hacia 1789.

Evidencias sobre la descendencia de las abuelas y de la abuela Stella Barona de los primeros esclavos libertos de la hacienda Cañasgordas que fundaron el caserío. En su tesis de grado para maestría, sobre el caserío, el coordinador Jorge Humberto Victoria hace referencia a que la comunidad se empieza a establecer a partir de 1852, y que fue el esclavo León Evangelista Barona quien construye la primera casa, la cual permanece con reformas estructurales y es denominada "Casa Paterna". El señor León es el abuelo de la abuela Stella Barona, quien, además, conoce muchas historias sobre ese proceso de esclavitud y poblamiento del caserío.

Indicios de la expropiación histórica al territorio del caserío Valle del Lili. Encontramos también que el territorio inicial de los primeros pobladores no fue invadido por ellos, sino que fue una donación de un predio de 90 plazas otorgado por el alférez real, don Manuel de Caicedo y Tenorio, según el relato de una de las abuelas (Victoria, J. et al., 1990). Pero este amplio territorio fue expropiado por terratenientes, quienes luego lo vendieron a las constructoras, que han ido edificando condominios con nombres alusivos, como "Plazoleta Cañasgordas, Point Valle del Lili, incluso se construyen campus universitarios", etc., que rodean las dos hileras de casas junto al rio Lili a las que hoy queda reducido el predio inicial del caserío. También contrastamos esta información con el recorte de prensa del periódico El Tiempo de 2005.

Rescate fotográfico de diferentes aspectos del caserío Valle del Lili. Motivados por el trabajo del grupo de investigación, tanto maestros como habitantes de la comunidad empezaron a aportar documentos, fotografías, recortes de prensa y testimonios de los procesos sociales, culturales y económicos del caserío. De estos, rescatamos un amplio registro fotográfico que no se conocía en la escuela, y el cual ni los estudiantes ni los maestros actuales habían podido apreciar; este da cuenta de los distintos momentos de evolución del caserío: su calle, sus construcciones, sus viviendas, sus linderos, los vestigios de sus puentes, que muestran 
el proceso comunitario de mejoramiento de las condiciones de vida. Estas fotografías ayudaron mucho a consolidar la investigación.

Los puentes del caserío. Gracias a esta investigación, comprendimos que la hacienda Cañasgordas mantenía una comunicación constante con el caserío Valle del Lili, a través de varios puentes viales y férreos, de los cuales pudimos descubrir vestigios registrados en fotografías, aunque, lastimosamente, ya no existe ninguno de ellos.

\section{Conocimiento de rasgos socioculturales de los prime-} ros habitantes del caserío. A través de la historia oral, del diálogo de saberes, de la salida de campo, de la consulta bibliográfica, de los archivos fotográficos y otros, descubrimos a las familias Gonzáles y Barona, directos descendientes de los esclavos y los primeros libertos de la hacienda Cañasgordas, cómo eran sus costumbres, sus creencias, el trabajo, las prácticas sociales y culturales, los castigos, la vivienda y la preparación de la comida tradicional, que aún se mantiene en algunas familias del caserío y forma parte de la comida típica caleña y vallecaucana: "El champús de Lola y el dulce de papaya verde o cabellos de ángel" o "la mazamorra de maíz pilao con lejía" que a diario se vende en triciclos por las calles del caserío. En estos talleres se daba no solo la receta, sino también el conocimiento histórico y cultural de las abuelas sobre aspectos de la vida como religiosidad, santería, noviazgo, cortejos, leyendas sobre el diablo, crianza de los hijos, vestuarios, etc.

En frases de los estudiantes, mencionamos algunos de los aprendizajes e interpretaciones:

"Cuando habían enfrentamientos, los esclavos se escondían bajo un hueco en la tierra y pasaban los amos en sus caballos y no se daban cuenta". "Hay sangre en la pared de la hacienda Cañasgordas porque castigaban a los afrodescendientes con un látigo de 12 nudos hasta sacarles sangre." (Zharick Ramos)

"La abuela Stella nos contaba sobre el castigo de los afros, pues los colgaban mirando al piso y los golpeaban en la espalda con un látigo con más de 12 nudos con chuzos hasta sacarle sangre". "También nos contaba sobre el noviazgo, y nos dijo que a los esclavos les pasaban un hacha pesada y le colocaban un pedazo de tronco, y si no lo rajaban no eran dignos de la muchacha". "Y también hacían una oración a Satanás para protegerse de los que le iban a lastimar, y si los apuñalaban no le hacían nada." (Paula Andrea Diossa)

“En el recorrido por el caserío, la señora doña Elena nos mostró un álbum; en el álbum pudimos observar fotografías de ardillas, pájaros de toda clase, guatines, nutrias... y las fotografías fueron tomadas por un vecino Ilamado don Álvaro." (Valeria Carvajal)

"Sobre la mazamorra, la abuela Stella dice que si se toma se debe reposar un rato, porque está caliente; y no se debe tomar agua, porque le da cólicos." (John Jairo)

\section{Conclusiones}

En lo relacionado con la metodología que se usó, esta fue la adecuada, de acuerdo con la edad de los niños, la cual oscila entre los 10 y los 12 años; en cuanto al tema de investigación, creemos que se hizo un trabajo de recopilación muy valioso, a través de la narración oral, el diálogo con las abuelas del caserío, así como las fuentes primarias representadas en archivos fotográficos, libros, tesis de grado y documentos.

La información oral aportada por la abuela Stella Barona y otros abuelos de la comunidad podría llegar a considerarse un insumo valioso de la historia oral de los afrodescendientes y parte del patrimonio cultural e inmaterial de la historia de la hacienda Cañasgordas, del caserío y de sus habitantes.

La vinculación y la aceptación de la comunidad del caserío Valle del Lili para participar en el proyecto fue muy importante, pues nos permitió manejar líneas de afectividad e identidad que dispusieron positivamente al grupo para escuchar, aprender y compartir los saberes.

Finalmente, nos surgieron más inquietudes y nuevas preguntas a partir de esta investigación:

- ¿Cómo llegaron los esclavos africanos al Valle del Cauca y a la antigua hacienda Cañasgordas? 
- ¿Cómo establecer la línea de parentesco y consanguinidad entre los primeros pobladores libertos de la hacienda Cañasgordas y algunos de los pobladores actuales del caserío Valle del Lili?

- ¿Cómo los habitantes del caserío, descendientes de esclavizados libertos, fueron perdiendo el territorio por cuenta de los terratenientes y los urbanizadores de la región, hasta quedar limitados a tan solo dos hileras de casas al margen del río Lili?

\section{Bibliografía aportada por la asesora como material de apoyo y consultada por el grupo de investigación}

Capítulo 1. La Hacienda un patrimonio nacional (2011). Recuperado de: https://www.youtube.com/watch?v=vwlRdimyw_U

Capítulo 2: Arqueología del relato (2011). Recuperado de: https:// www.youtube.com/watch? $v=$ gdSJhJNniRo

Capítulo 3: Hormiguero. La herencia de Cañasgordas (2011). Recuperado de: https://www.youtube.com/watch? $v=-$ WoP dnY9j8

\section{Video visto en uno de los talleres}

El Pueblo. La investigación arqueológica, un aliento para la Hacienda Cañasgordas. Recuperado de: http://elpueblo.com. co/la-investigacion-arqueologica-un-aliento-para-la-haciendacanasgordas/\#ixzz3jgZkQUD2

Ocampo, A. \& Cuesta, G. (2011). Antología de mujeres poetas afrocolombianas. Biblioteca de Literatura Afrocolombiana, Tomo XVI. Ministerio de Cultura.

\section{Referencia Bibliográfica}

Palacios, Eustaquio. (Edición del año 2010). El Alférez Real. Cali.

Patiño, German. Fogón de negros-2010

\section{Diálogo del conocimiento}

\section{Los actos de recuerdo como didáctica de la historia escolar}

El Valle del Cauca y el Cauca constituyen una compleja región cuya historia social, política y cultural tiene tremendas implicaciones en la vida presente de la nación colombiana. Durante la larga etapa colonial, el trabajo de indios en las encomiendas y africanos esclavizados en minas, haciendas y plantaciones, produjeron la riqueza de una horrenda empresa sostenida en la clasificación socio-racial de las personas y su desmedida explotación.

En muchas de las escuelas del suroccidente colombiano, y del resto del país, los y las estudiantes poco saben sobre la cultura material e inmaterial que se produjo en las antiguas haciendas de Cali, Popayán, Palmira, Buga o Bogotá. Muy por el contrario, sucede que enseñamos una historia alejada de la vida cotidiana, de los lugares por donde transitan los chicos, de los edificios que guardan esa larga memoria de las personas, las culturas y las formas de relacionamiento que forjaron nuestra realidad actual. Estas razones hacen sobresalientes y altamente significativos los esfuerzos de maestras y maestros ocupados de investigar con sus estudiantes el pasado de sus comunidades y sus familias, pues esta labor pedagógica, además de enriquecer el campo de la enseñanza de las ciencias sociales escolares, ofrece una increíble y maravillosa aventura identitaria, en la cual indagar el pasado, es al mismo tiempo reconstruir el espejo del presente, y comprender las piezas que explican los apellidos, los fenotipos, el origen de clase, el tono de la piel de las personas contemporáneas e incluso los nombres de los lugares.

El camino que recorre el proyecto "Herencia afrodescendiente en el caserío Valle del Lili", de la Institución Educativa Técnica de Ballet Clásico INCOLBALLET, en la ciudad de Cali, es una experiencia que contribuye a formar en los jóvenes la capacidad de pensar históricamente la vida social de la cual hacen parte. Igualmente, en su trabajo sobre la memoria y la historia oral con las personas mayores de la localidad, este proyecto entabla un diálogo de saberes intergeneracionales, que permite lo que Carretero, Rosa \& González han señalado como "actos de recuerdo": 
Los actos del recuerdo siempre están al servicio de las acciones presentes, se recuerdan para que se pueda sentir, evocar, imaginar, desear o sentirse impelido a hacer algo, aquí y ahora, o en un futuro más o menos próximo. Lo importante es lo que queremos hacer, o que se haga; y lo menos importante es que el recuerdo sea exacto, que la re-presentación sea lo más parecido posible a lo que sucedió en el pasado. Lo que nos importa es que el recuerdo sirva para los propósitos de la acción presente. (Carretero, Rosa \& González, 2006, pp. 20-21)

Este proyecto, narrado en la voz del profesor Alejandro Astorquiza, representa una nueva ventana para mirar el tratamiento de la memoria en la escuela. Como lo señala el docente, una hacienda como Cañasgordas no solo es un testimonio de la antigua arquitectura colonial, es al mismo tiempo un territorio simbólico que produce recuerdos y emociones colectivas, donde, con el paso del tiempo, se han tejido y heredado de boca en boca, versiones sobre los hechos ocurridos en el pasado. El mejor modo de decir todo esto es retomando las palabras de una de las estudiantes vinculadas a este trabajo: "Hay sangre en la pared de la hacienda Cañasgordas porque castigaban a los afrodescendientes con un látigo de 12 nudos hasta sacarle sangre" (Ramos).

Elizabeth Castillo Guzmán

\section{Referencias}

Carretero, M., Rosa, A. \& González, M. (Comp.) (2006). Enseñar historia en tiempos de memoria En Enseñanza de la historia y memoria colectiva (pp. 11-36). Buenos Aires: Paidós. 